\title{
SOCIO-DEMOGRAPHIC STATUS AND ALCOHOL DRINKING PATTERNS AMONG GREEK HEALTHY ADULTS
}

\author{
Pandelis Pazarlis ${ }^{1}$, Davide Mauri ${ }^{1}$, Ivan Cortinovis ${ }^{2}$, Konstantinos Katsigiannopoulos ${ }^{1}$, Paraskevi Alevizaki ${ }^{1}$, \\ Georgios Koukourakis ${ }^{1}$, Giovanni Casazza ${ }^{2}$, Konstantinos Kamposioras ${ }^{1}$, loanna Chatziioannou ${ }^{1}$, \\ Athansios Milousis ${ }^{1}$, Anastasios Papakonstantinou ${ }^{1}$, Ioanna Karathanasi ${ }^{1}$, George Alexiou ${ }^{1}$, \\ Anastasios Proiskos ${ }^{1}$, Zoi Mitrogianni ${ }^{1}$, Christina Peponi ${ }^{1}$ \\ ${ }^{1}$ Panhellenic Association for Continual Medical Research (PACMeR) Sections of Public-Health, Athens, Greece \\ ${ }^{2}$ Institute of Medical Statistics and Biometry, University of Milano, Italy
}

\section{SUMMARY}

Aim: To analyze socio-demographic correlates of alcohol drinking among Greek healthy adults.

Methods: Data related to alcohol consumption patterns of 5,500 adult individuals, coming from 26 Hellenic provinces were abstracted from SESy-Europe database within a framework of the nationwide Hellenic anticancer-trial PACMeR 02 study. Statistic: $\chi^{2}$ test and logistic regression analyses were used.

Results: $42.5 \%$ of males and $82.5 \%$ of females did not consume alcoholic drinks. Among users, daily alcohol assumption was $28.50 \mathrm{~g} / \mathrm{day}$ for men and $9.85 \mathrm{~g} /$ day for women. The mainland population presented higher proportions for both abstainers and moderate-heavy drinkers. Consumption rate was higher for sub-populations living in islands, but they were mostly light drinkers rather than heavy consumers. Among males, younger subjects, farmers and craftsmen had a higher tendency for alcohol abuse. Among females, the proportion of consumers and abusers was notably more elevated among younger individuals, especially among those living in urban areas of mainland, with higher educational level, employees and freelance professionals. A particular attention to the newly and rapidly growing patterns of alcoholism among young females should be given and prevention programs should be promptly developed.

Key words: alcohol, socio-demographic status, healthy adults, Greece

Address of correspondence: P. Pazaralis, Kleanthous 5, Evosmos TK 56224, Thessalonikki, Greece. E-mail: kostdoc@hotmail.com

\section{INTRODUCTION}

Alcohol intake is a world-spread, long-standing habit. Since ancient times alcohol has been a method of creating euphoria (1) and a form of entertainment for people $(2,3)$.

Over the last decades alcohol consumption has become particularly widespread $(4,5)$ often surpassing the accepted limit and reaching the point of abuse $(6,7)$. Alcohol-abuse influences users' quality of life to a large extent $(5,8-11)$ and increases the liability to physical illness such as metabolic, cardiovascular and neoplastic diseases $(2,5,12-14)$. As a consequence it represents a major public-health issue.

Alcohol-usage indicators among American, Asian and European population have rapidly increased over the last few years $(3,4,15-17)$, but little is known about alcohol-intake habits among Hellenic healthy adults. In the last two decades only one nationwide survey was reported in literature (18). Apart from the San Jose et al. study (18), previous publications retrieved their data from a survey conducted in 1984 (19-21).

Therefore little is known about the actual alcohol consumption among the Hellenic adult population, and there are no reports on the contemporary nationwide geographical drinking patterns (e.g. islands versus mainland) and the relationship between alcohol intake and type of community (urban vs. rural areas) or working patterns (e.g. handicraftsmen vs. freelance professionals). The purpose of this study was to describe the main socio-demographic characteristics of alcohol users in a nationwide sample of Hellenic healthy people.

Considering that our study involved healthy adult population (mean age 60.35 years old, standard deviation 10,9) we hypothesized that both civil status (married vs. single) and presence and number of sons may modify alcohol consumption patterns. These hypotheses were therefore verified. Furthermore, considering that light and moderate drinkers may experience health benefit from alcohol consumption due to the reduction of overall mortality rates, myocardial infarction, stroke and coronary heart disease (22-29) we evaluated the level of alcohol consumption among users.

\section{METHODS}

PACMeR 02 study is a large survey organized by PACMeR (Panhellenic Association for Continual Medical Research) and 


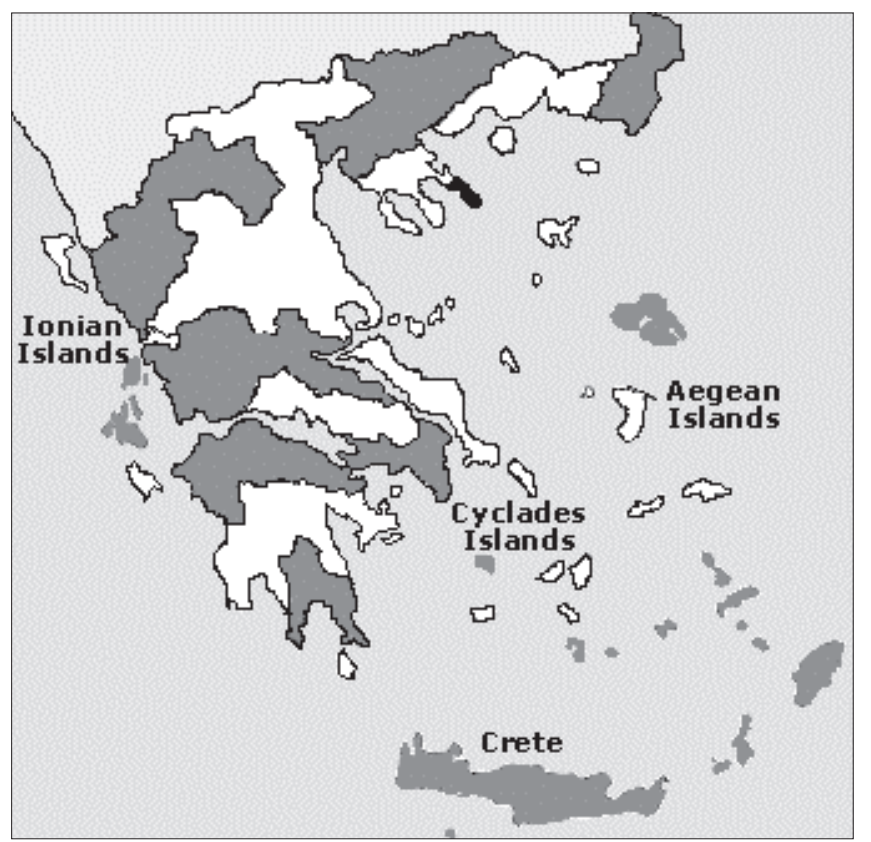

Fig. 1. Map of Greece: areas involved in the study (grey).

targeted to estimate cancer preventive and screening practices among the Hellenic asymptomatic adults population. As investigational instrument, the study employed two tailored questionnaires (one for males and one for females), which had been developed and validated in a feasibility study in August - September 2000. Estimation of alcohol consumption patterns among the Hellenic adult population was initially a by-product of the study; anyhow, due to the lack of data in medical literature, it became a major outcome of PACMeR 02 study in 2002, and the alcohol related questions of the questionnaires were implemented. The exact rephrasing is provided in the supplementary note for the facilitation of the peer-review process.

The project was ethically approved by PACMeR's Scientific Committee (protocol number 08_020720) and conformed to the ethical guidelines of the 1975 Declaration of Helsinki. A written informed consent form was obtained from all the participants before completing the study questionnaire and the data retrieved were analyzed in anonymous and codified form.

Population was composed by a nationwide convenience sample: healthy adults able to bring their relatives for interview while getting healthcare in Hospitals and Health Centers of 26 Hellenic provinces. Since the most populated areas were involved (Fig. 1), the Hellenic population coverage was higher than $80 \%$. 5,500 individuals (2,948 females, 2,552 males, age range 21-97) entered the study and answered the questionnaires during a faceto-face interview between 2000 to 2004 .

Ninety two physicians employed in primary care activities were involved in the study, 87 of them as interviewers. Data storing was assured by SESy_Europe Database a 3-component multi-language database $(30,31)$ dedicated to population-based cross-sectional surveys for cancer prevention and screening practices.

According to the domains of the questionnaires in years 2000-2002 and 2002-2004 (see Appendix) the alcohol-related data stored in SESy_Europe database (Hellenic version), may be broken down for 5 categories.
- Non-alcohol users (abstainers)

- Alcohol-users for whom there was available the description of the type and quantity of alcohol intake: beer, wine, distilled spirits.

- Alcohol-users for whom there was no description regarding the type and quantity of alcohol intake.

- Former alcohol-users for whom there was available the description of the type and quantity of alcohol intake.

- Former alcohol-users without description of the type and quantity of alcohol intake.

For the socio-demographic analysis, detailed socio-demographic parameters were available for each individual.

Taking into consideration that alcohol consumption varies by age and is more common among males, the subjects involved in the study were divided by gender in the following age-risk categories: <45, 45-64, 65-74 and >75.

We further analyzed the consumption patterns by the following parameters: education level (illiterate vs. primary vs. secondary vs. university education); social status (married vs. single [free or divorced or widower]); number of sons (0-1 vs. 2 vs. 3 or more); type of community (urban vs. rural areas), geographical area (mainland vs. Crete Island vs. Aegean Island and Ionian Island); job categories. Job categories were classified as follow: craftsmen, clerks and employees, farmers, freelance professionals, pensioners, housewives, other professions.

Alcohol intake was converted into grams of pure ethanol consumption per week. The grams of ethanol consumed for an average week was estimated from reported drinking frequency, beverage type and average amount of consumption based on the ethanol content of standard drinks. Drinking patterns were classified into four categories according to Graziano and Hennekens (32): abstainers, light-drinkers, moderate-drinkers and heavy-drinkers. In particular heavy drinkers were defined as men who drink more than $400 \mathrm{~g}$ or women who drink more than $280 \mathrm{~g}$ of alcohol per week. Men who drank less than 169 and women $112 \mathrm{~g}$ per week were designated as light drinkers. Moderate drinkers have been designated as men who drank between 168 and $400 \mathrm{~g} /$ week or women betweeen 280 and $112 \mathrm{~g} /$ week. Those who did not drink at all were defined as abstainers.

Statistical analysis: The association between socio-demographic characteristic and alcohol patterns were analysed using $\chi^{2}$ test. For each gender we performed a logistic regression to analyse characteristics that were majorly predictive of alcohol consumption. Confidence intervals of odds ratios were computed by Wald procedure.

\section{RESULTS}

Sample Characteristics: There was a significant difference in the age distribution of female and male individuals involved in the survey $\left(\chi_{3}^{2}=332.9, \mathrm{p}<0.001\right)$ largely driven by the higher proportion of women included in the age group $<45$ years old (14.3\% for women vs. $2.3 \%$ for men). Questionnaire for males was in fact focused on people older than 45 years (for colorectal and prostate cancer screening), while questionnaire for females was targeted even to younger ages due to cervical and breast cancer screening practice. Gender distribution per age-group is reported in 


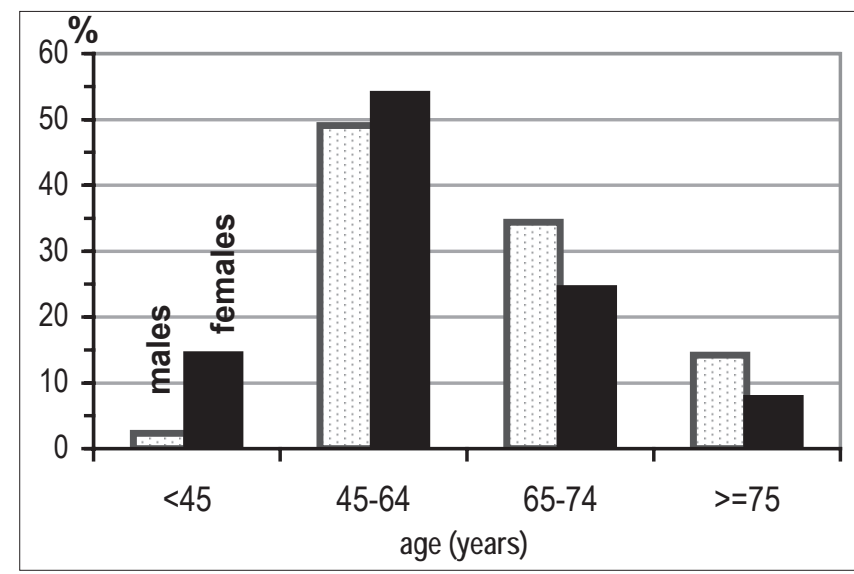

Fig. 2. Proportion of males and females in each age-group.

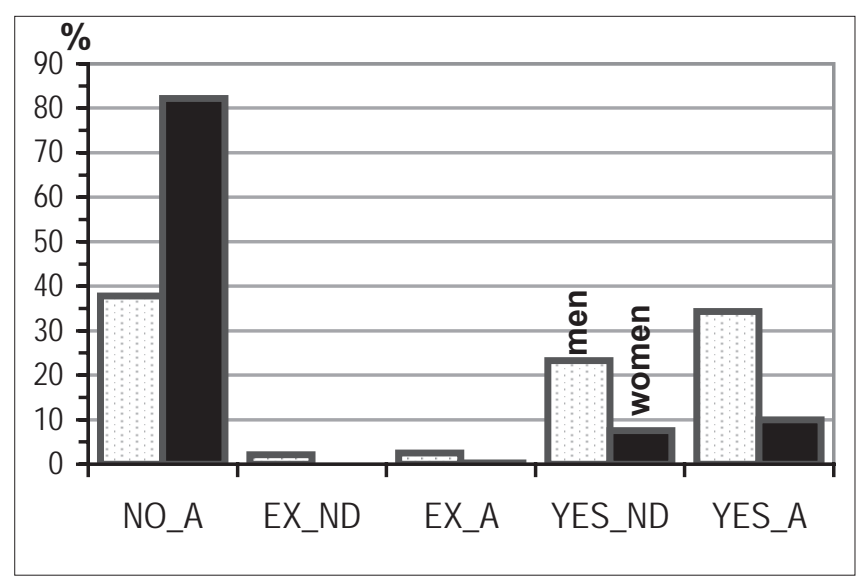

Fig. 3. Total sample: habit to drink alcohol by gender.

Legend:

abstainers (NO_A); former alcohol-users for whom there was available (EX_A) or not (EX ND) the description of the type and quantity of alcohol intake; alcohol-users with description (YES_A) and without description (YES_ND) for the type and quantity of alcohol intake. Gender significantly influenced alcohol consumption patterns, $\chi^{2}=1140.3, p<0.0001$, but it did not have any impact on the availability of qualitative data of alcohol consumption among drinkers (ND vs. A) $\chi^{2}=1.02$ ( $p>0.05$ n.s.)

Fig. 2. As a consequence the mean age of male individuals involved in the study was consistently higher, 63.4 years old (standard error 0.19) compared with 57.7 years old (standard error 0.21 ) in women respectively. Furthermore, analysis by gender of the proportion of population using alcohol, showed that consumption patterns were statistically higher among men than in women $\left(\chi_{4}^{2}=1,140.3, \mathrm{p}<0,0001\right)$ (Fig. 3).

In the overall examined sample of Hellenic adult individuals, we found that $42.5 \%$ of males did not consume alcoholic drinks (37.8\% abstainers and $4.7 \%$ ex-users), this proportion being significantly higher among females $(82.5 \% ; 82.2 \%$ abstainers and $0.3 \%$ ex-consumers). Conversely, among users, daily quantity of alcohol consumption was consistently higher in men $(28.50$ $\mathrm{g} /$ day, standard error 1.27$)$ than in women $(9.85 \mathrm{~g} /$ day, standard error 0.85).

Considering the significance of gender for alcohol consumption, all variables examined were analysed for each gender separately (Table 1).
Mean time of exposure, in years of alcohol consumption between users was 36.7 years $(\mathrm{SE}=0.58)$ for men vs. 24.6 years $(\mathrm{SE}=1.0)$ for women.

Among alcohol users, the proportion who drink only wine was $59 \%$ for males vs. $75 \%$ for females, while for those drinking only hard liquor it was $18.4 \%$ vs. $7.6 \%$, respectively. The $7 \%$ of male vs. $4.5 \%$ of female users declared drinking only beer. In the other cases the type of alcohol consumption was mixed (15.6\% for men, $12.5 \%$ for women).

Age: We observed differences in alcohol use across distinct age groups in both genders $(\mathrm{p}<0.0001)$. Among women aged over 75 years, the proportion of abstainers was notably higher (89.9\%), while it was lower in females younger than 45 years $(70.2 \%)$. Similarly the proportion of men with no alcohol consumption was higher among individuals older than 75 (44.3\%) and lower among those younger than 45 years (27.6\%). When compared with female gender, male population displayed higher rate of alcohol use for any of the age-subgroups analysed.

The proportion of former alcohol drinkers was lower than $1 \%$ for any female age-subgroup. The proportion of men who discontinued alcohol consumption ranged between $3.4 \%$ for males younger than 45 , to $5.9 \%$ for those older than 75 years.

Education: Statistical differences observed in educational patterns $(p=0.0002)$ were largely driven by female gender. Drinking patterns among women displayed significant differences $(\mathrm{p}<0.0001)$, with the proportion of abstainer decreasing in parallel with the educational level $(88.8 \%$ for illiterates vs. $85.8 \%$ for primary education vs. $81.2 \%$ for secondary education vs. $26.76 \%$ for university education).

Among men alcohol consumption was more common in illiterate individuals and those with secondary education.

Civil Status: Among women we found that single (27.6\%) and divorced females $(22.0 \%)$ had higher frequency of alcohol use when compared with married women $(17.2 \%)$ or widows $(11.9 \%)$, but the reported differences were not statistically significant $(\mathrm{p}=0.8466)$.

The proportion of male subjects consuming alcohol was quite uniform among the analyzed categories $(p=0.4029)$ with divorced individuals displaying lower rates of alcohol use (55\%) when compared with the other subgroups (57.1-62.7\%).

Number of Sons: The variable "number of sons" seems not to have any impact on drinking patterns $(\mathrm{p}=0.7918)$; neither when male gender $(p=0.7178)$ or female gender were considered separately $(p=0.1192)$.

Community: Residence (urban vs. rural) did not play an important role in overall analysis. When male individuals were considered we found that there was a fair but statistical difference $(p=0.014)$ in alcohol consumption (urban users $33.9 \%$ vs. nonurban users $34.8 \%$ ).

Islands vs. Land: The proportion of individuals consuming alcohol was notably higher in Crete island $(21.8 \%)$ and mainland (20.8\%). Among men the proportion of alcohol consumers was lower in the islands (about 30\%) than in the mainland (30.8\%).

Among women the association with habit of alcohol is week $(p=0.039)$, in mainland it seems higher proportion of abstainers ( $4 \%$ about) than in the islands.

Profession: Weak statistical differences were found for the proportion of individuals consuming alcohol when professionsubgroups were analysed for the overall population, as well as for 
Table 1. Composition of habit alcohol within gender for different variables

\begin{tabular}{|c|c|c|c|c|c|c|c|c|}
\hline & & \multicolumn{3}{|c|}{ Men $(2,552)$} & & \multicolumn{3}{|c|}{ Women $(2,948)$} \\
\hline & No. & $\begin{array}{l}\text { Abstainers } \\
(37.8 \%)\end{array}$ & $\begin{array}{l}\text { Others } \\
(27.9 \%)\end{array}$ & \begin{tabular}{|l} 
YES_A \\
$(34.3 \%)$
\end{tabular} & No. & $\begin{array}{l}\text { Abstainers } \\
(82.2 \%)\end{array}$ & $\begin{array}{l}\text { Others } \\
(7.9 \%)\end{array}$ & $\begin{array}{l}\text { YES_A } \\
(9.9 \%)\end{array}$ \\
\hline Age (years) & $\left(6\right.$ d.f. $\left.{ }^{* *}\right)$ & & & & $\left(6\right.$ d.f. $\left.{ }^{* *}\right)$ & & & \\
\hline$<45$ & 58 & 27.6 & 39.6 & 32.8 & 413 & 70.2 & 15.0 & 14.8 \\
\hline $45-64$ & 1,239 & 34.1 & 30.5 & 35.4 & 1,552 & 82.7 & 7.6 & 9.7 \\
\hline $65-74$ & 870 & 41.4 & 25.3 & 33.3 & 707 & 85.8 & 5.9 & 8.3 \\
\hline$\geq 75$ & 357 & 44.3 & 22.9 & 32.8 & 219 & 89.9 & 2.3 & 7.8 \\
\hline Education & $\left(6\right.$ d.f. $\left.{ }^{* *}\right)$ & & & & $\left(6\right.$ d.f. $\left.{ }^{* *}\right)$ & & & \\
\hline no education & 132 & 47.0 & 13.6 & 39.4 & 172 & 88.9 & 3.5 & 7.6 \\
\hline primary & 1,290 & 35.0 & 31.3 & 33.7 & 1,552 & 83.8 & 6.4 & 9.8 \\
\hline secondary & 761 & 39.9 & 24.2 & 35.9 & 858 & 81.2 & 8.8 & 10.0 \\
\hline university & 237 & 43.9 & 28.7 & 27.4 & 213 & 71.8 & 12.2 & 16.0 \\
\hline Urban area & $(2$ d.f. *) & & & & (2 d.f. ns) & & & \\
\hline yes & 1,043 & 40.2 & 25.0 & 34.8 & 1,320 & 80.8 & 7.8 & 11.4 \\
\hline Territorial area & $\left(4\right.$ d. f. $\left.{ }^{* *}\right)$ & & & & $(4$ d. f. *) & & & \\
\hline Mainland & 1,776 & 42.8 & 21.5 & 35.7 & 2,023 & 83.3 & 7.2 & 9.5 \\
\hline Ionian and Aegean islands & 134 & 29.8 & 38.9 & 31.3 & 216 & 80.0 & 11.6 & 9.0 \\
\hline Crete & 604 & 25.0 & 44.2 & 30.8 & 655 & 79.4 & 9.0 & 11.6 \\
\hline Married & (2 d. f. ns) & & & & & & & \\
\hline yes & 2,308 & 38.1 & 27.9 & 34.0 & 2,537 & 82.4 & 7.7 & 9.9 \\
\hline Number of sons & (4 d. f. ns) & & & & & & & \\
\hline $0-1$ & 449 & 37.2 & 25.4 & 37.4 & 611 & 79.2 & 9.6 & 11.1 \\
\hline 2 & 1,225 & 37.8 & 27.7 & 34.5 & 1,354 & 83.0 & 7.3 & 9.7 \\
\hline 3 or more & 778 & 35.4 & 31.2 & 33.4 & 880 & 83.9 & 7.0 & 9.1 \\
\hline Profession & $\left(10\right.$ d. f. $\left.{ }^{* *}\right)$ & & & & $\left(10\right.$ d. f. $\left.{ }^{* *}\right)$ & & & \\
\hline Craftsmen & 326 & 31.0 & 32.2 & 36.8 & 97 & 81.4 & 11.4 & 7.2 \\
\hline Clerks and employees & 494 & 38.7 & 25.7 & 35.6 & 544 & 75.4 & 11.7 & 12.9 \\
\hline Farmers & 657 & 31.3 & 32.2 & 36.5 & 321 & 85.0 & 5.3 & 9.7 \\
\hline Freelance professionals & 327 & 36.1 & 26.9 & 37.0 & 147 & 78.2 & 10.9 & 10.9 \\
\hline Pensioners & 478 & 50.8 & 21.2 & 28.0 & 267 & 88.0 & 6.0 & 6.0 \\
\hline Housewives & 3 & 0.0 & 0.0 & 100.0 & 1,405 & 84.5 & 6.5 & 9.0 \\
\hline Other labor conditions & 242 & 40.1 & 30.2 & 29.7 & 121 & 68.6 & 12.4 & 19.0 \\
\hline
\end{tabular}

Yes_A: Alcohol users for whom there was available the description of the type and quantity of alcohol intake

Others: Alcohol users without description of the type and quantity of alcohol intake and former users

ns $=p>0.05$

$*=0.005<p<0.001$

** $=p<0.01$

$\mathbf{d f}=$ degree of freedom

gender. The proportions of people drinking alcoholic beverages by gender and profession-category are shown in details in Table 1. Craftsmen and freelance professional for the men and clerk for the women seem to be the professions with the high percentage of alcohol users.

Body Mass Index (BMI): We found that the overall population analyzed was overweight in all the categories considered. Among men mean BMI was 27.17 (standard error 0.07), while among women it was 27.27 (standard error 0.09). We have not found any correlation between BMI and patterns of alcohol consumption.

Logistic Regression: In order to provide a predictive risk of alcohol consumption we performed for each gender a compre- hensive analysis including all the above mentioned socio-demographic categories. For this analysis we used only individuals included in the following two subgroups: abstainers, and users of alcoholic drinks for whom there was available the description of the type of alcohol intake. In order to avoid subgroups with an excessively low sample size some variables were grouped (civil status: married vs. not married; profession: male "housewives" were grouped with others, female craftsmen were grouped with others). Therefore we analyzed only data that may better represent the situation of alcohol consumption without any information bias. Due to the alcohol consumption patterns in the two genders, the logistic regression analysis for alcohol consumption was better balanced for men than for women. 
Table 2. Logistic regression: backward procedure selected two variables both for men (land area and occupation) and women (age and urban area) that may respectively predict for more than $50 \%$ and $48 \%$ of the alcohol consumption habits

\begin{tabular}{|l|l|l|l|l|}
\hline & Model & No. of variables & d.f. & Likelihood ratio \\
\hline \multirow{4}{*}{ Men } & full model & 7 & 17 & 55.48 \\
\cline { 2 - 6 } & selected model & 2 & 7 & 41.61 \\
\cline { 2 - 5 } & $\begin{array}{l}\text { (territorial area } \\
\text { and occupation) }\end{array}$ & & & \\
\hline \multirow{4}{*}{ Women } & full model & 7 & 17 & 35.10 \\
\cline { 2 - 6 } & selected model & 2 & 4 & 21.39 \\
\cline { 2 - 5 } & $\begin{array}{l}\text { (age and } \\
\text { community) }\end{array}$ & & & \\
\hline
\end{tabular}

d. f. = degree of freedom

Using logistic regression, the backward procedure selected 2 variables for men (land area and occupation) that may illustrate and predict more than $50 \%$ of the alcohol consumption habits. Even among women the obtained model used 2 variables (age and urban area) to predict $48 \%$ of alcohol-intake behaviours (Table 2). Calculated odds ratios and related confidence intervals for each of the two models are reported in Table 3.

Among men we noted a "protective" odds ratio value for individuals living in Crete with respect to those living in the continent. Farmers and craftsmen seemd to be less exposed to alcohol use than other professions.

Among females we found that the risk of drinking is directly correlated with the age. Older women showed greater exposure

Table 3. Calculated odds ratios and related confidence intervals for each of the two models

\begin{tabular}{|l|l|l|l|}
\hline & \multicolumn{1}{|c|}{ OR } & \multicolumn{2}{c|}{$95 \%$ C.I. } \\
\hline MEN & & & \\
\hline Land Area & & & \\
\hline Mainland & 1 & & \\
\hline Islands & 0.786 & 0.494 & 1.253 \\
\hline Crete & 0.696 & 0.543 & 0.893 \\
\hline Type of profession & & & \\
\hline Others & 1 & & \\
\hline Handicraftsmen & 0.646 & 0.419 & 0.995 \\
\hline Employes and clercks & 0.815 & 0.549 & 1.209 \\
\hline Freelance professionals & 0.702 & 0.461 & 1.068 \\
\hline Farmers & 0.630 & 0.431 & 0.923 \\
\hline Pensioners & 1.270 & 0.855 & 1.886 \\
\hline WOMEN & & & \\
\hline Age & & & \\
\hline$<45$ & 1 & & \\
\hline $45-64$ & 1.763 & 1.259 & 2.471 \\
\hline $65-74$ & 2.008 & 1.347 & 2.996 \\
\hline$\geq 75$ & 2.489 & 1.343 & 4.614 \\
\hline Community & & & \\
\hline Rural & 1 & & \\
\hline Urban area & 0.756 & 0.584 & 0.977 \\
\hline & & & \\
\hline
\end{tabular}

than those younger than 45 years. Furthermore, women living in urban areas are at lower risk of alcohol use than those living in non urban areas (Table 3).

Alcohol Consumption Patterns Among Drinkers (Table 4): Among men: Farmers showed the highest rate of moderate and heavy alcohol users while clerks the highest proportion of light-drinkers. This distribution of alcohol consumption within the different professions was not statistically significant $\left(\chi_{15}^{2}=24.58, p=0.0559\right)$. When the type of community was considered, alcohol consumers living in rural areas presented the highest proportion of moderate-drinkers and heavy-drinkers, while those leaving in urban areas were light-drinkers. The reported differences were statistically significant $\left(\chi_{6}^{2}=19.16\right.$, $\mathrm{p}<0.01$ ). Wine consumers were mostly light drinkers. Heavy drinkers were mostly associated with the consumption of multiple type of beverages $\left(\chi_{21}^{2}=3005.5, \mathrm{p}<0.0001\right)$. No difference in the distribution of low-, moderate-, and heavy-alcohol use were found to be associated with age, civil status, number of sons and obesity.

Among women: The proportion of consumers of female gender is low and very low are particularly heavy drinkers $(3.5 \%)$. Young women are more frequently consumers than older ones. Among users the proportion of light-drinkers is notably higher. There is anyway the impression that among females, the alcoholic beverage use is a newly acquired habit therefore affecting mostly the young generation for all the consumption categories analysed: light-, moderate- and heavy-drinkers $\left(\chi_{9}^{2}=25.19\right.$, $\mathrm{p}<0.01$ ). This impression was further confirmed by the fact that moderate-drinking and heavy-drinking females were mostly resident of urban areas of the Hellenic mainland, and the major part of them were freelance professionals or clerks and employees. Despite the evidence, we can only speak about trends, since the absolute number of female moderate-drinker and heavy-drinker is low, so no statistically significant associations might be taken into account for the above mentioned variables (type of community, profession, and land type). We still observed a statistically significant relationship between educational status and drinking patterns, with the higher educational levels being the most exposed $\left(\chi_{9}^{2}=19.61, p=0.025\right)$. Similarly with male gender, female heavy-drinkers were mostly consumers of multiple type of beverages. No difference in the distribution of light-, moderate-, and heavy-drinkers were found to be associated to civil status, number of sons and obesity.

\section{DISCUSSION}

In the last 2 decades only one survey investigated the socio-demographic characteristics of alcohol consumers among a nationwide sample of the Hellenic adults (18).

The present report is the first study to analyze the contemporary geographical (mainland vs. islands), working and community patterns of alcohol intake among a large convenience sample of the Hellenic population. This is of great importance for Greece, a country of $131,957 \mathrm{~km}^{2}$ surface area, consisting of a peninsula and over 2000 islands (33). Differences between the greater area of Athens vs. the rest of Greece has been documented in literature $(18,20)$. We noted that island sub-populations (especially the Cretan one) have increased alcohol consumption pattern when 
Table 4. Patterns of drinkers within gender for different variables

\begin{tabular}{|c|c|c|c|c|c|c|c|c|}
\hline & & \multicolumn{3}{|c|}{ Men (865) } & & \multicolumn{3}{|c|}{ Women (289) } \\
\hline & No. & \begin{tabular}{|l} 
Light \\
$(61.4 \%)$
\end{tabular} & $\begin{array}{l}\text { Moderate } \\
(23.9 \%) \\
\end{array}$ & $\begin{array}{l}\text { Heavy } \\
(14.6 \%)\end{array}$ & No. & $\begin{array}{l}\text { Light } \\
(85.71 \%)\end{array}$ & \begin{tabular}{|l} 
Moderate \\
$(10.8 \%)$
\end{tabular} & \begin{tabular}{|l} 
Heavy \\
$(3.5 \%)$
\end{tabular} \\
\hline Age (years) & (6 d. f. ns) & & & & (6 d. f. ns) & & & \\
\hline$<45$ & 19 & 73.7 & 15.8 & 10.5 & 61 & 78.7 & 16.4 & 4.9 \\
\hline $45-64$ & 439 & 60.1 & 22.5 & 17.3 & 150 & 84.7 & 10.7 & 4.7 \\
\hline $65-74$ & 289 & 63.7 & 26.6 & 9.7 & 59 & \begin{tabular}{|l|}
93.2 \\
\end{tabular} & 6.8 & 0.0 \\
\hline$\geq 75$ & 117 & 59.0 & 23.9 & 17.1 & 17 & 94.1 & 5.9 & 0.0 \\
\hline Education & (6 d. f. ns) & & & & (6 d. f. ns) & & & \\
\hline no education & 52 & 55.8 & 25.0 & 19.2 & 13 & 69.2 & 30.8 & 0.0 \\
\hline primary & 434 & 57.6 & 26.0 & 16.4 & 147 & 89.8 & 7.5 & 2.7 \\
\hline secondary & 273 & 68.1 & 20.1 & 11.7 & 86 & 81.4 & 13.9 & 4.6 \\
\hline university & 65 & 67.7 & 21.5 & 10.8 & 34 & 85.3 & 8.8 & 5.9 \\
\hline Urban area & $\left(2\right.$ d. f. $\left.{ }^{* *}\right)$ & & & & (2 d. f. ns) & & & \\
\hline yes & 362 & 67.7 & 19.1 & 13.2 & 151 & 85.4 & 9.9 & 4.7 \\
\hline Territorial area & (4 d. f. ns) & & & & (4 d. f. ns) & & & \\
\hline Mainland & 634 & 58.5 & 24.6 & 16.9 & 193 & 83.9 & 11.9 & 4.1 \\
\hline Ionian and Aegean islands & 42 & 61.9 & 30.9 & 7.1 & 18 & 94.4 & 5.6 & 0.0 \\
\hline Crete & 186 & 71.0 & 21.0 & 8.0 & 76 & 88.2 & 9.2 & 2.6 \\
\hline Married & (2 d. f. ns) & & & & (2 d. f. ns) & & & \\
\hline yes & 784 & 61.4 & 23.7 & 14.9 & 251 & 86.8 & 10.4 & 2.8 \\
\hline Number of sons & (4 d. f. ns) & & & & (4 d. f. ns) & & & \\
\hline $0-1$ & 159 & 62.3 & 25.2 & 12.6 & 68 & 91.2 & 4.4 & 4.4 \\
\hline 2 & 422 & 62.3 & 23.0 & 14.7 & 131 & 89.3 & 8.4 & 2.3 \\
\hline 3 or more & 260 & 59.6 & 24.2 & 16.1 & 80 & 82.5 & 15.0 & 2.5 \\
\hline Profession & (10 d. f. ns) & & & & $(10$ d. f. *) & & & \\
\hline Craftsmen & 119 & 60.5 & 25.2 & 14.3 & - & - & - & - \\
\hline Clerks and employees & 176 & 69.3 & 19.9 & 10.8 & 70 & 77.1 & 17.1 & 5.7 \\
\hline Farmers & 240 & 56.2 & 27.9 & 15.8 & 31 & 77.4 & 19.3 & 3.2 \\
\hline Freelance professionals & 121 & 64.5 & 23.1 & 12.4 & 16 & 62.5 & 25.0 & 12.5 \\
\hline Pensioners & 134 & 61.2 & 23.9 & 14.9 & 16 & 100.0 & 0.0 & 0.0 \\
\hline Housewives & - & - & - & - & 126 & 92.1 & 5.6 & 2.4 \\
\hline Other labor conditions & 75 & 56.0 & 21.3 & 22.7 & 30 & 93.3 & 6.7 & 0.0 \\
\hline
\end{tabular}

ns $=$ p $>0.05$

* $=0.005<p<0.001$

$* *=p<0.01$

compared with mainland, but their practice is mostly associated to use of alcohol (light drinkers), rather than abuse of the substance (moderate or heavy drinkers). Considering the U or J-shaped health effects of alcohol consumption patterns, the increased alcohol intake seems to benefit the island populations rather than constitute a form of abuse. On the opposite mainland populations were found to be mostly abstainers and displaying a higher proportion of moderate and heavy drinkers. When professions were considered we found that males, farmers and craftsmen had a tendency for both use and abuse, while clerks and employees, in spite of being frequent consumers, were mostly light drinkers.

The proportion of both light and heavy consumers was dramatically augmented among younger women, especially among those living in urban areas of mainland, with higher educational levels namely among employees or freelance professionals. While considering that young women may have transition (age-related) out of problematic consumption patterns, our data still suggest that alcohol consumption among females may be a newly acquired habit. It seems that the way of female emancipation will increase the proportion of women consuming alcoholic drinks in any consumption pattern. Prompt attention should be given to the prevention of alcohol abuse among the younger generations.

Older age groups were more likely to be abstainers or light consumers, thus confirming other data previously reported in literature $(18,21)$. As elsewhere discussed (18) interpretation of age-related data should be cautious among adult populations since patterns of alcohol abuse may be biased by the selection mecha- 
nisms of increased morbidity and mortality among heavy users. No difference in the distribution of heavy-drinkers were found to be associated to civil status, number of sons and obesity.

This study presents the following limitations: Similarly with the previously nationwide report of San Jose et al. that was conducted within a framework of the Hellenic component of the EPIC study (18), our trial used data abstracted from SESy-Europe database (Screening Evaluation System_Europe database) within a framework of the nationwide Hellenic anticancer-trial PACMeR 02. The evaluation of alcohol consumption patterns was therefore a by-product of the first part of the study and a small under-reporting bias was thus possible. For these reasons the information coming from the first part of the trial was not included in the meta-regression analysis. PACMeR 02 study was conducted in a one to one interview form. Interview-based study presents generally the risk of under-reporting bias (34) and are not anonymous. The potential reduction of the privacy related bias was anyway potentially overcome by the one-to-one form of the interview, and by the presence of a primary care physician as interviewer, thus facilitating both confidentiality and true answers. Furthermore, despite all medical doctors employed underwent a brief educational workshop, the use of physicians as interviewers may still be associated with under-reporting of light-drinkers. Particularly, in physicians' daily practice, people consuming less than one glass of wine every two (or more) weeks and sporadical light-drinkers are more likely to be classified as non-users rather than users. Therefore, while the proportion of moderate and heavy drinkers is expected to be accurate due to the insightful presence of physician interviewers, the proportion of light-drinkers is expected to be under-estimated in favor of the abstainers group.

\section{CONCLUSIONS}

Allowing for the afore-mentioned caveats, we conclude that our findings may be of value in defining a more targeted national anti-alcoholism health-policy based on socio-demographic evidence. The nationwide characteristics of the sample may help health providers in focusing educational interventions on high-risk groups. A particular attention to the newly and rapidly growing patterns of alcoholism among young females should be given and prevention programs should be promptly developed.

\section{Supplementary note:}

Exact phrasing of the alcohol-related questions used for both males and females during the questionnaire-based interviews in the period 2000-2002 and 2002-2004.

2000-2002 phrasing of alcohol-related questions

Do you drink alcoholic drinks? [No] [yes]

Describe how much do you drink?

How old did you start drinking alcoholic drinks?
2002-2004 phrasing of alcohol-related questions

\begin{tabular}{|c|c|}
\hline Do you drink alcoholic drinks? & {$[\mathrm{No}]$} \\
\hline $\begin{array}{l}\text { How old did you start drinking } \\
\text { alcoholic drinks? }\end{array}$ & {$\left[\begin{array}{ll}{[}\end{array}\right]$} \\
\hline $\begin{array}{l}\text { How old did you stop drinking } \\
\text { alcoholic drinks? }\end{array}$ & [ ] \\
\hline How much wine do you drink? & \\
\hline How much beer do you drink? & \\
\hline How much hard liquor do you drink? & \\
\hline
\end{tabular}

In both periods the following Hellenic beverages (raki, ouzo, tsikoudia, metaxa and tsipouro) were considered distilled spirits (like grappa, whisky or vodka).

\section{Acknowledgments}

Dr Aliki Ioakimidou (PACMeR: sections of Microbiology and Public Health); Dr Anastasia Mastrogianni (Psychiatrist, Psychiatric Hospital of Thessalonikki), Dr Georgios Kouris \& Parthenopi Alexandropoulou (Dept.Internal Meicine, General Hospital of Lixouri, Island of Cephalonia), Dr George Pentheroudakis (Dept. Medical Oncology, University Hospital of Ioannina).

\section{REFERENCES}

1. Liappas JA, Lascaratos J, Fafouti S, Christodoulou GN. Alexander the Great's relationship with alcohol. Addiction. 2003 May;98(5):561-7.

2. Oscar-Berman M, Marinkovic K. Alcoholism and the brain: an overview. Alcohol Res Health. 2003;27(2):125-33.

3. Bloomfield K, Stockwell T, Gmel G, Rehn N. International comparisons of alcohol consumption. Alcohol Res Health. 2003;27(1):95-109.

4. Galvan FH, Caetano R. Alcohol use and related problems among ethnic minorities in the United States. Alcohol Res Health. 2003;27(1):87-94.

5. Hasin D. Classification of alcohol use disorders. Alcohol Res Health. 2003;27(1):5-17.

6. Gunzerath L, Faden V, Zakhari S, Warren K. National Institute on Alcohol Abuse and Alcoholism report on moderate drinking. Alcohol Clin Exp Res. 2004 Jun;28(6):829-47.

7. Oswald LM, Wand GS. Opioids and alcoholism. Physiol Behav. 2004;81(2):339-58.

8. Pirkola SP, Suominen K, Isometsa ET. Suicide in alcohol-dependent individuals: epidemiology and management. CNS Drugs. 2004;18(7):42336.

9. Hybels CF, Blazer DG. Epidemiology of late-life mental disorders. Clin Geriatr Med. 2003 Nov;19(4):663-96.

10. Beullens J, Aertgeerts B. Screening for alcohol abuse and dependence in older people using DSM criteria: a review. Aging Ment Health. 2004 Jan;8(1):76-82.

11. Peters TJ, Millward LM, Foster J. Quality of life in alcohol misuse: comparison of men and women. Arch Womens Ment Health. 2003 Nov;6(4):239-43.

12. Poschl G, Stickel F, Wang XD, Seitz HK. Alcohol and cancer: genetic and nutritional aspects. Proc Nutr Soc. 2004 Feb;63(1):65-71.

13. Chrostek L, Szmitkowski M. Alcohol and risk for the cancer. Pol Merkuriusz Lek. 2003 Nov;15(89):487-90. (In Polish.)

14. Hillbom M, Pieninkeroinen I, Leone M. Seizures in alcohol-dependent patients: epidemiology, pathophysiology and management. CNS Drugs. 2003;17(14):1013-30.

15. Kuntsche E, Rehm J, Gmel G. Characteristics of binge drinkers in Europe. Soc Sci Med. 2004 Jul;59(1):113-27.

16. Poldrugo F. Homogenizing alcoholism treatment across Europe. J Neural Transm Suppl. 2003;(66):97-111.

17. Room R. Effects of alcohol controls: Nordic research traditions. Drug Alcohol Rev. 2004 Mar;23(1):43-53. 
18. San Jose B, Lagiou P, Chloptsios Y, Trichopoulou A. Sociodemographic correlates of abstinence and excessive drinking in the Greek population. Subst Use Misuse. 2001 Mar;36(4):463-75.

19. Madianos MG, Madianou D, Stefanis C. Familial correlates of drug and alcohol use in a nationwide general population survey. Psychopathology. 1995;28(2):85-94.

20. Madianos MG, Gefou-Madianou D, Stefanis CN. Drinking practices of illicit and licit drug users in the general population across Greece. Am J Drug Alcohol Abuse. 1994 Nov;20(4):547-59.

21. Madianos MG, Gefou-Madianou D, Stefanis C. Patterns of alcohol consumption and related problems in the general population of Greece. Addiction. 1995 Jan;90(1):73-85.

22. Marmot MG, Rose G, Shipley MJ. Alcohol and mortality. Lancet. 1981 May 23;1(8230):1159.

23. Baum-Baicker C. The psychological benefits of moderate alcohol consumption: a review of the literature. Drug Alcohol Depend. 1985 Aug;15(4):305-22.

24. Camacho TC, Kaplan GA, Cohen RD. Alcohol consumption and mortality in Alameda County. J Chronic Dis. 1987;40(3):229-36.

25. Rehm J, Sempos CT. Alcohol consumption and all-cause mortality. Addiction. 1995 Apr;90(4):471-80.

26. Stampfer MJ, Colditz GA, Willett WC, Speizer FE, Hennekens CH. A prospective study of moderate alcohol consumption and the risk of coronary disease and stroke in women. N Engl J Med. 1988 Aug 4;319(5):267-73.

27. Marques-Vidal P, Ducimetiere P, Evans A, Cambou JP, Arveiler D. Alcohol consumption and myocardial infarction: a case-control study in France and Northern Ireland. Am J Epidemiol. 1996 Jan 1;143(11):1089-93.
28. Rodgers H, Aitken PD, French JM, Curless RH, Bates D, James OF. Alcohol and stroke. A case-control study of drinking habits past and present. Stroke. 1993 Oct;24(10):1473-7.

29. San Jose B, van de Mheen H, van Oers JA, Mackenbach JP, Garretsen HF. The U-shaped curve: various health measures and alcohol drinking patterns. J Stud Alcohol. 1999 Nov;60(6):725-31.

30. Mauri D, Pazarlis P, Mauri J, Altinoz H, Rivas Flores FJ, Karentzou I, et al. SESy-Europe: a multi-language database dedicated to cancer screening monitoring. J Exp Clin Cancer Res. 2004 Sep;23(3):441-5.

31. Mauri J, Mauri D, Pazarlis P, Altinoz H, Rivas Flores FJ, Karentzou I, et al. PC 3-component database for community-based medical trials. A costeffective solution both for voluntary associations and for institutions of the "Emerging World". Gazz Med Ital - Arch Sci Med. 2004;163(5):18994.

32. Gaziano JM, Hennekens C. Royal colleges' advice on alcohol consumption. BMJ. 1995 Jul 1;311(6996):3-4.

33. Media info 2004: Media services for the Olympic Games [homepage on the Internet]. Athens: Hellenic Republic - Secretariat General of Communication, Secretariat General of Information [cited 2006 Oct 10]. Greece in brief: Geography; [about 3 screens]. Available from: http://www. mediainfo2004.gr/cgibin/hweb?-A=297\&-V=greece\&-w.

34. Neve RJ, Diederiks JP, Knibbe RA, Drop MJ. Developments in drinking behavior in The Netherlands from 1958 to 1989, a cohort analysis. Addiction. 1993 May;88(5):611-21.

Received April 4, 2006

Received in revised form and accepted August 14, 2006 